\title{
Some new research outcomes of wolframite-tin- polymetallic metallization in the Huoi Chun area, Huaphanh province, Lao people's democratic republic (LPDR)
}

\author{
Tri Cong Luu ${ }^{1}$, Huan Dinh Trinh ${ }^{1}$, Tu Minh Chu ${ }^{2}$, Ha Xuan Dinh ${ }^{1}$, Phuong Nguyen ${ }^{3, *}$ \\ ${ }^{1}$ Northern Geological Mapping Division, Vietnam \\ ${ }^{2}$ Geological Division for Radioactive and Rare Elements, Vietnam \\ ${ }^{3}$ Faculty of Environment, Hanoi University of Mining and Geology, Vietnam
}

ARTICLE INFO
Article history:
Received 11 ${ }^{\text {th }}$ Feb. 2020
Revised 06 ${ }^{\text {th }}$ Mar. 2020
Accepted 29th Apr. 2020

Keywords:
Huaphanh province,
Huoi Chun tungsten,
Lao People's Democratic
Republic (LPDR),
TIN - Polymetallic
metallization.

ABSTRACT

The paper introduces several new research results on the metallization of wolfram, tin - polymetallic in Huoi Chun area based on the application of traditional geological methods combining with the research method of ore material composition and the statistical mathematics. The research results draw some conclusions: Ore minerals in Huoi Chun area are formed mainly by the way of material deposition, crystallized from hydrothermal solution, filling various fracture systems with different development directions. The main minerals in the region are wolfram, tin, copper, zinc and bismuth; the metallization of wolfram, tin-polymetallic is formed during the hydrothermal ore creation, including three stages corresponding to three mineral paragenesis assemblage; in particular, the mineral paragenesis assemblage of the abiogenesis wolframite bismuth is a new discovery of the authors. The $\mathrm{Sn}, \mathrm{Cu}, \mathrm{Pb}, \mathrm{Zn}$, As and $\mathrm{Cd}$ elements have a relatively close correlation with each other, which is a specific combination of elements for the II (two) mineralization phase and the W, Co and Bi elements is typical for the III (three) mineralization phase of the hydrothermal ore creation period. The metallization of wolfram, tin - polymetallic is formed which might be related to the intrusive magma activity that occurred during the Mesozoic - Cenozoic period (?).

Copyright (C) 2020 Hanoi University of Mining and Geology. All rights reserved.

${ }^{*}$ Corresponding author

E-mail: phuongmtmdc@gmail.com

DOI: 10.46326/JMES.2020.61(2).03 


\title{
Tạp chí Khoa học Kỹ thuật Mỏ - Địa chất
}

Trang điện tử: http://tapchi.humg.edu.vn

\section{Một số kết quả nghiên cứu mới về quặng hóa wolfram, thiếc-đa kim khu vực Huổi Chừn, tỉnh Hủa Phăn, Cộng hòa Dân chủ Nhân dân Lào}

\author{
Lưu Công Trí ${ }^{1}$, Trịnh Đình Huấn ${ }^{2}$, Chu Minh Tú ${ }^{2}$, Đinh Xuân Hà ${ }^{1}$, Nguyễn Phương ${ }^{3, *}$ \\ ${ }^{1}$ Liên đoàn bản đồ Địa chất miền Bắc, Việt Nam \\ 2 Liên đoàn Địa chất Xạ - Hiếm, Việt Nam \\ ${ }^{3}$ Khoa Môi trường, Trường Đại học Mỏ - Địa chất, Việt Nam
}

THÔNG TIN BÀI BÁO

Quá trình:

Nhận bài $11 / 02 / 2020$

Sửa xong $06 / 3 / 2020$

Chấp nhận đăng 29/4/2020

Tù̀ khóa:

CHDCND Lào,

Quặng hóa wolfram,

Thiếc - đa kim khu vực

Huổi Chừn,

Tỉnh Hủa Phăn.

\section{TÓM TẮT}

Bài báo giới thiệu một số kết quả nghiên cúu mới về quặng hóa wolfram, thiếc - đa kim khu vực Huổi Chừn trên cơ sở áp dụng phương pháp địa chất truyền thống, kết hợp phương pháp nghiên cưu thành phần vật chất quặng và phương pháp toán thống kế. Kết quả nghiên cứu rút ra một số kết luận sau: Các khoáng vật quặng trong khu vực Huổi Chù̀n được thành tạo chủ yếu theo phương thức lăng đọng vật chất, kết tinh tù̀ dung dịch nhiệt dịch, lấp đầy các hệ thống khe nứt có phương phát triển khác nhau. Khoáng sản chủ đạo trong khu vực là wolfram, thiếc, đồng, kẽm, bismut; Quăng hóa wolfram, thiếc - đa kim được thành tạo trong thòi kỳ tạo quặng nhiệt dịch, gồm 3 giai đoạn tương úng với 3 tổ hợp công sinh khoáng vật; trong đó, tổ hợp công sinh khoáng vật wolframit - bismut tự sinh là phát hiện mói của tập thể tác giả. Các nguyển tố $S n, C u, P b, Z n, A s$ và Cd có mối quan hệ tương quan khá chặt chẽ với nhau, là tổ hợp nguyên tố đặc trung cho giai đoạn tạo khoáng II và các nguyên tố $W$, Co và Bi đặc trưng cho giai đoạn tạo khoáng III của thò̀ kỳ tạo quặng nhiệt dịch. Quặng hóa wolfram, thiếc - đa kim được hình thành có thể có liên quan đến hoạt động magma xâm nhập xảy ra trong giai đoạn Merozoi - Kainozoi (?).

C 2020 Trường Đại học Mỏ - Địa chất. Tất cả các quyền được bảo đảm.

\section{Mở đầu}

Quặng wolfram, thiếc - đa kim Huổi Chừn được phát hiện lần đầu vào năm 1974 trong công tác đo vẽ bản đồ địa chất và tìm kiếm khoáng sản tỷ lệ

*Tác giả liên hệ

E - mail: phuongmtmdc@gmail.com DOI: 10.46326/JMES.2020.61(2).03
1:200.000 tờ Sầm Nưa (CHDCND Lào). Trong giai đoạn 1974 - 1975, Đoàn Địa chất C103 (thuộc Liên đoàn $\mathrm{C}$, nay là Liên đoàn Intergeo) tiếp tục tiến hành một số dạng công tác tìm kiếm và đã phát hiện được hơn 30 điểm khoáng hóa, trong đó quặng thiếc, đa kim (chì, kẽm, đồng) chiếm ưu thế (Tô Văn Thụ, 1982). Quặng hóa khu vực Huổi Chừn thuộc kiểu wolfram, thiếc - đa kim phân bố ở bờ phải suối Nậm Gioong và Nậm Căn thành hai vùng (vùng Huổi Van và vùng Bắc - Đông Bắc). 
Các thân quặng chủ yếu nằm trong đá phiến thạch anh felspat - biotit thuộc tập 2 hệ tầng Mường $\mathrm{Na}\left(\mathrm{PR}_{2} m n_{2}\right)$. Thân quặng có dạng thấu kính, dạng đới mạch lấp đầy trong đới phá huỷ, được khống chế bởi đứt gãy lớn phương á vĩ tuyến và phương Đông Bắc - Tây Nam (Hình 1). Cạnh mạch phổ biến các hiện tượng chlorit hoá, thạch anh hóa. Kết quả phân tích quang phổ bán định lượng xác định các nguyên tố $\mathrm{Mg}, \mathrm{Fe}, \mathrm{Mn}, \mathrm{Ti}, \mathrm{V}, \mathrm{Ba}$, $\mathrm{Cr}, \mathrm{Cu}, \mathrm{Ag}$, Pb, Zn, Ga, Zr, Ni, Co, Sn, Bi; trong đó, hàm lượng thiếc đạt đến 3\% (Tô Văn Thụ, 1982).

Trong khuôn khổ chuyến khảo sát thực địa thuộc đề tài Nghị định thư Việt - Lào, mã số NĐT.35.LA/17 tại tỉnh Hủa Phăn, nhóm tác giả đã tiến hành lấy mẫu phân tích khoáng tướng và phân tích ICP-MS 23 nguyên tố. Kết quả phân tích cho thấy hàm lượng wolfram trong các mẫu rãnh lấy tại vết lộ có giá trị khá cao (một số mẫu đạt trên 4.000 ppm). Các khoáng vật wolframit, bismut tự sinh xuất hiện nhiều dưới dạng lấp đầy trong các

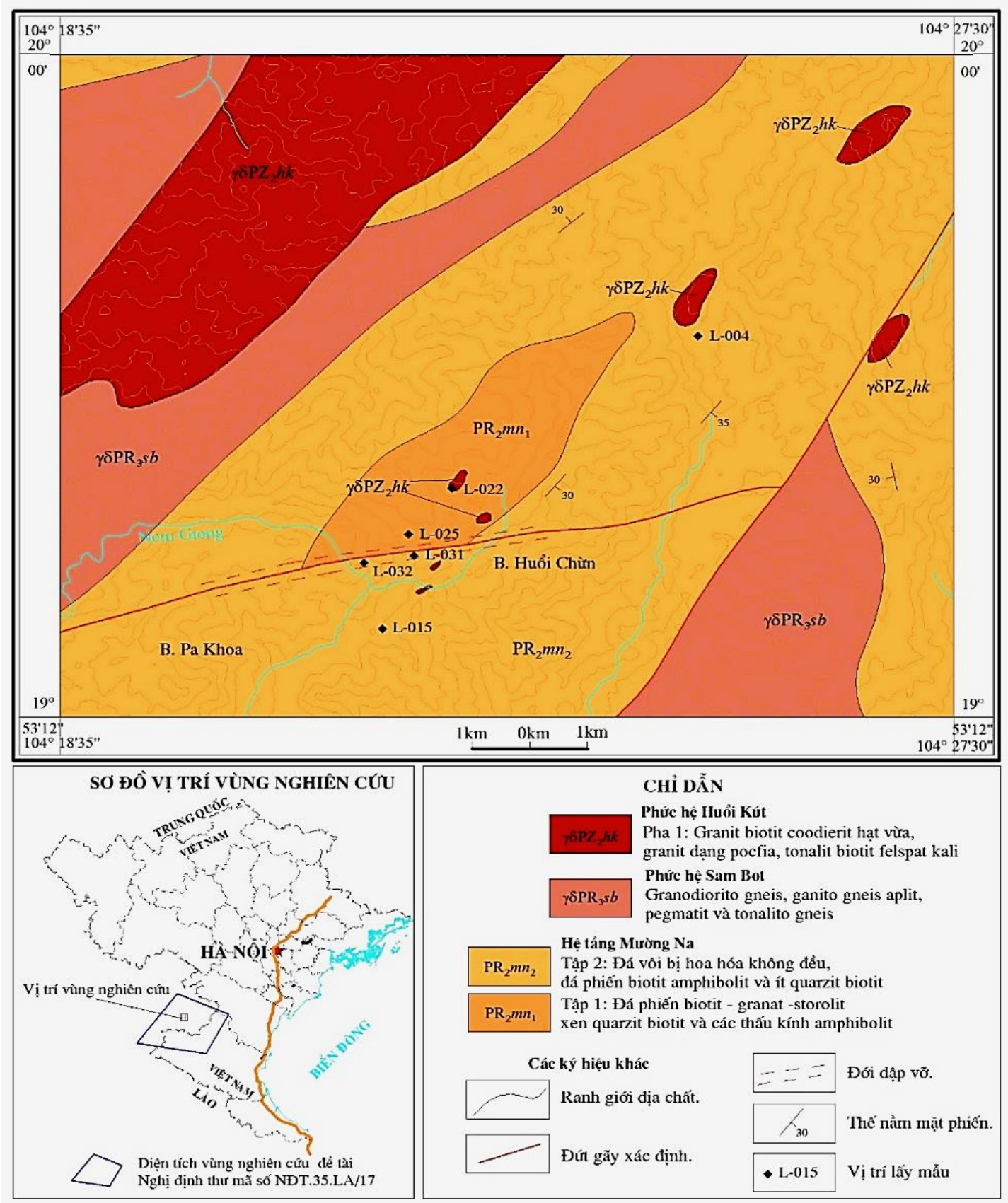

Hình 1. Sơ đồ địa chất - khoáng sản và vị trí lấy mẫu vùng nghiên cúu (Tô Văn Thụ, 1982; Vũ Đức Lân, 2016). 
vi mạch thạch anh nhiệt dịch hoặc thay thế, gặm mòn các khoáng vật quặng sulfur hình thành trước. Điều đó cho thấy, wolfram không phải là quặng hóa đi kèm mà là khoáng vật quặng chủ đạo được thành tạo ở giai đoạn tạo quặng muộn. Đây là phát hiện mới của tập thể tác giả và rất cần được tiếp tục nghiên cứu.

Bài báo công bố một số kết quả nghiên cứu mới về quặng hóa wolfram, thiếc - đa kim trên cơ sở tổng hợp tài liệu có trước và kết quả nghiên cứu mới đạt được bước đầu trong quá trình thưc hiện đề tài Nghị định thư Việt - Lào, mã số NĐT.35.LA/17 khu vực Huổi Chừn, tỉnh Hủa Phăn nước CHDCND Lào.

\section{Khái quát đặc điểm địa chất khu vực}

Khu Huổi Chừn thuộc phức nếp lồi Sầm Tớ, là phần kéo dài về phía Tây Bắc của Đới biến chất cao Phu Hoạt (Dovjicov, 1965; Trần Văn Trị, Vũ Khúc, 2009). Trên lãnh thổ CHDCND Lào, phức nếp lồi Sầm Tớ bắt đầu từ Nậm Dít, Mường Quắn, Mường $\mathrm{Na}$, Pa Khao, Nọng Kham vót dần về phía bản Nọng Khai và bị chìm xuống dưới các trầm tích trẻ hơn (Dovjicov, 1965; Tô Văn Thụ, 1982; Trần Văn Trị, Vũ Khúc, 2009). Cấu thành nên phức nếp lồi Sầm Tớ trong vùng nghiên cứu là một loạt các đá trầm tích - biến chất tuổi cổ thuộc hệ tầng Mường $\mathrm{Na}$ $\left(\mathrm{PR}_{2} m n\right)$ có thành phần đa dạng và được chia làm hai tập:

- Tập $1\left(\mathrm{PR}_{2} m n_{1}\right)$ : gồm đá phiến kết tinh như đá phiến thạch anh - biotit chứa granat, đá phiến thạch anh - biotit có xen lẫn quarzit biotit; chuyển tiếp lên trên là các đá thuộc tập 2.

- Tập $\left(\mathrm{PR}_{2} m n_{2}\right)$ : gồm đá phiến thạch anh felspat - biotit xen lẫn các tập đá vôi bị hoa hóa không đều và các thấu kính amphibolit (Hoàng Phương và nnk., 1974; Lê Duy Bách, Nguyễn Văn Hoành, 1996). Các đá trên phân bố rộng rãi trong khu vực nghiên cứu và phát triển kéo dài theo phương Đông Bắc - Tây Nam.

Hoạt động magma xâm nhập trong khu vực xảy ra mạnh mẽ qua nhiều giai đoạn (Lê Duy Bách, 1996; Tô Văn Thụ, 1982). Ở phía Tây Bắc và Đông Nam khu vực nghiên cứu là các đá xâm nhập phức hệ Sam Bot $\left(\gamma \delta \mathrm{PR}_{3} s b\right)$. Thành phần thạch học chủ yếu gồm granodiorit và granit pegmatit bị biến dạng mạnh, cấu tạo dạng gneis, bị xuyên cắt bởi granit biotit hạt nhỏ thuộc phức hệ Huổi Kút $\left(\gamma \delta \mathrm{PZ}_{2} h k\right)$. Phần trung tâm diện tích nghiên cứu xuất hiện các khối nhỏ granit biotit phức hệ Huổi
Kút xuyên cắt lên các đá trầm tích - biến chất hệ tầng Mường $\mathrm{Na}$, ranh giới xuyên cắt quan sát rõ tại một số vị trí. Hoạt động đứt gãy, uốn nếp trong phức nếp lồi Sầm Tớ xảy ra mạnh mẽ vào cuối Merozoi, đầu Kainozoi hình thành nên đứt gãy lớn có phương á vĩ tuyến và các đứt gãy nhánh phương Đông Bắc - Tây Nam (Dovjicov, 1965; Tô Văn Thụ, 1982; Trần Văn Trị, Vũ Khúc, 2009). Quặng hóa W, Sn - đa kim khu vực Huổi Chừn phân bố trong các mạch thạch anh nhiệt dịch xuyên cắt các đá biến chất hệ tầng Mường Na. Các nghiên cứu chi tiết về đặc điểm thành phần vật chất quặng và tổ hợp cộng sinh khoáng vật còn khá sơ lược. Một số tác giả trước đây đã nhận định: quặng wolfram được thành tạo có liên quan đến hoạt động magma xâm nhập xảy ra trong giai đoạn Mesozoi - Kainozoi (Nguyễn Văn Đễ, 1974; Vũ Huy Chừng, 1974).

\section{Các phương pháp nghiên cứu}

\subsection{Phương pháp địa chất truyền thống, kết hơp thu thập, tổng hợp xử lý tài liệu}

- Thu thập, tổng hợp tài liệu, đánh giá độ tin cậy của các nguồn tài liệu thu thập được từ các nguồn tài liệu có trước (Dovjicov, 1965; Trần Văn Trị, Vũ Khúc, 2009; Pham Nhu Sang nnk., 2020; Nguyen Huu Hiep nnk., 2020; Tô Văn Thụ, 1982; Trần Văn Trị, Vũ Khúc, 2009, Lê Duy Bách, 1996; Tô Văn Thụ, 1982).

- Lộ trình khảo sát địa chất thực tế, thu thập tài liệu ở các vết lộ tự nhiên và lấy các loại mẫu phân tích (Hình 1).

\subsection{Các phương pháp nghiên cứu thành phần vật chất quặng}

Để nghiên cứu thành phần vật chất quặng, ngoài tổng hợp phân tích thành phần vật chất các nghiên cứu trước $(2,3,4,7)$, nhóm tác giả đã lấy và phân tích bổ sung một số loại mẫu sau:

- Phân tích khoáng tướng dưới kính hiển vi phân cực phản quang Carl Zeiss - Axio-Scope. Al, nguồn sáng halogen. Kết quả phân tích đã xác định rõ hơn về thành phần khoáng vật, kiến trúc, cấu tạo quặng và mối quan hệ của các khoáng vật trong quặng.

- Thành phần hóa học quặng được xác định bằng phương pháp phân tích khối phổ plasma (ICP-MS) trên thiết bị Sciex ELAN 6000 của hãng Perkin Elmer với độ chính xác cao. Các phân tích 
được thực hiện tại Cục Địa chất Nhật Bản.

\subsection{Phưong pháp trong phòng}

\subsubsection{Mô hình toán thống kê một chiều}

Trong thực tế nghiên cứu, để có hình ảnh tổng quát về đối tượng nghiên cứu, số liệu thu thập phải được xử lý tổng hợp, trình bày, tính toán nhằm đánh giá độ tin cậy và tính đại diện của các mẫu thu thập từ các nguồn tài liệu khác nhau; mặt khác kết quả đó sẽ giúp chúng ta khái quát hóa được đặc trưng tổng thể về đối tượng nghiên cứu. Trong xử lý tài liệu địa chất khoáng sản, các nhà nghiên cứu thường sử dụng quy luật phân bố chuẩn, loga. Khai thác mô hình, nói cách khác là dựa vào các quy luật hàm phân bố thống kê đã quy nạp để xác định các đặc trưng thống kê $(\bar{X}, D, V)$ của thông số nghiên cứu là nhiệm vụ quan trọng cần giải quyết.

\subsubsection{Phương pháp thống kê hai chiều}

Phương pháp cho phép đánh giá những biến đổi tương ứng với những yếu tố nhất định, cũng như đánh giá tần số xuất hiện các giá trị nhất định của thành phần các nguyên tố trong quặng hoặc trong thực thể địa chất nào đó. Trong thực tế, người ta thường sử dụng phương pháp thống kê hai chiều, đa chiều để xác định sự phụ thuộc tương quan giữa các thông số với nhau. Trong bài báo, nhóm tác giả sử dụng mô hình thống kê hai chiều với sự trợ giúp của phần mềm Excel để xác định mối quan hệ tương quan giữa các nguyên tố. Hệ số tương quan phản ánh mối quan hệ tương quan giữa hai nguyên tố $x, y$ ký hiệu là $R_{x}$ và xác định theo công thức:

$R_{x y}=\frac{\sum_{i=1}^{n} x_{i} y_{i}-\frac{1}{n} \sum_{i=1}^{n} x_{i} \sum_{i=1}^{n} y_{i}}{\sqrt{\left[\sum_{i=1}^{n} x_{i}^{2}-\frac{1}{n}\left(\sum_{i=1}^{n} x_{i}\right)^{2}\right]\left[\sum_{i=1}^{n} y_{i}^{2}-\frac{1}{n}\left(\sum_{i=1}^{n} y_{i}\right)^{2}\right]}}$

Trong đó: $x_{i} y_{i}$ lần lượt là giá trị của nguyên tố $x$ và $y$ tại mẫu thứ $i ; n$ là số mẫu.

Khi $r_{x y}>0$ thì $x$ và $y$ có mối quan hệ thuận; $r_{x y}<0$, giữa $x$ và $y$ có mối quan hệ nghịch.

\section{Kết quả và thảo luận}

\section{1. Đặc điểm thành phần vật chất quặng}

\subsection{1. Đặc điểm thành phần khoáng vật}

Tổng hợp tài liệu có trước và kết quả phân tích 15 mẫu khoáng tướng bổ sung, cho thấy thành phần khoáng vật quặng điểm Huổi Chừn chủ yếu gồm: chalcopyrit, pyrit, pyrorin, bismut tự sinh, galenit, sphalerit, wolframit; các khoáng vật quặng thứ yếu gồm casiterit, ilmenit, rutil, leucoxen, menhilcovit, lilianit,... và các khoáng vật phi quặng. Dưới đây chỉ mô tả các khoáng vật quặng gặp phổ biến trong các mẫu phân tích khoáng tướng

- Wolframit: Khoáng vật có tần suất xuất hiện ở mức độ trung bình, chiếm khoảng $5 \div 10 \%$ trong bộ mẫu. Wolframit tồn tại ở dạng hạt nửa tự hình, ranh giới tiếp xúc với các khoáng vật khác thường không rõ ràng, kích thước các hạt khoáng vật dao động từ $0,1 \div 0,3 \mathrm{~mm}$. Hầu hết các mẫu có sự xuất hiện của wolframit đều nhận thấy các hạt khoáng vật có độ nổi cao và thường tồn tại ở 2 dạng kiến trúc: i) Thay thế, gặm mòn các khoáng vật thành tạo trước như chalcopyrit, pyrit (Hình 1a, 1b); ii) Xen lấp vào giữa các khoáng vật thành tạo trước (Hình 1c, 1d). Với 2 dạng kiến trúc trên cho thấy khoáng vật wolframit hình thành ở giai đoạn sau.

- Chalcopyrit: Khoáng vật có tần suất xuất hiện cao trong tập mẫu, gồm 2 thế hệ: Chalcopyrit I chiếm khoảng $40 \div 45 \%$, tồn tại ở dạng hạt tha hình, kích thước các hạt khá lớn từ $0,6 \div 0,8 \mathrm{~mm}$, đôi chỗ tập trung thành từng đám, có ranh giới tiếp xúc phẳng với pyrotin $\mathrm{I}$, pyrit I, tạo thành một tổ hợp cộng sinh khoáng vật thuộc giai đoạn tạo khoáng thứ nhất (Hình 1a, 1b, 1c, 1d). Chalcopyrit thế hệ I bị gặm mòn, xen lấp bởi các khoáng vật wolframit, bismut tự sinh. Chalcopyrit II chiếm $5 \div 8 \%$, tồn tại ở dạng hạt nửa tự hình, kích thước các hạt từ $0,1 \div 0,3 \mathrm{~mm}$ xâm tán độc lập trên nền đá (Hình $1 \mathrm{j})$.

- Pyrotin: Khoáng vật có tần suất xuất hiện cao trong tập mẫu. Pyrotin có 2 thế hệ: pyrotin I chiếm khoảng $10 \div 15 \%$, tồn tại ở dạng hạt tha hình, kích thước các hạt phổ biến từ $0,3 \div 0,4 \mathrm{~mm}$ đôi chỗ tập trung thành đám, pyrotin I thường đi cùng với chalcopyrit I, pyrit I, tạo thành 1 tổ hợp khoáng vật thuộc giai đoạn tạo khoáng thứ nhất (Hình $1 \mathrm{a}, 1 \mathrm{c}$, 1d). Pyrotin thế hệ I thường bị gặm mòn, xen lấp bởi các khoáng vật wolframit, bismut tự sinh, sphalerit. Pyrotin II chiếm 5\%, dạng hạt nửa tự hình, phân bố xâm tán độc lập trên nền đá (Hình $1 \mathrm{k})$.

- Pyrit: Có tần suất xuất hiện cao, chiếm khoảng $25 \div 30 \%$. Pyrit trong tập mẫu gồm 2 thế hệ: Pyrit I tồn tại ở dạng hạt tha hình với kích thước hạt dao động từ $0,4 \div 0,6 \mathrm{~mm}$ xuất hiện cùng với chalcopyrit và pyrotin thế hệ I tạo thành một tổ 
hợp cộng sinh khoáng vật thuộc giai đoạn tạo khoáng thứ nhất (Hình 1f, 1h). Pyrit II tồn tại ở dạng hạt tự hình, xâm tán độc lập trên nền đá.

- Galenit: Xuất hiện với số lượng ít trong tập mẫu khoáng tướng, chiếm khoảng $3 \div 5 \%$. Quan sát dưới kính cho thấy galenit tồn tại ở dạng hạt tha hình với kích thước hạt khoáng vật trung bình là $0,05 \mathrm{~mm}$, bề mặt phẳng, có nhiều vết xước. Galenit xuất hiện đồng thời với sphalerit thành một tổ hợp cộng sinh khoáng vật (Hình 1f).

- Sphalerit: Khoáng vật có tần suất xuất hiện thấp, chiếm khoảng $5 \div 7 \%$ tập mẫu. Sphalerit tồn tại ở dạng hạt tha hình với kích thước hạt từ $0,1 \div 0,3 \mathrm{~mm}$. Trong các mẫu có mặt sphalerit cho thấy khoáng vật này cùng với galenit tạo thành một tổ hợp cộng sinh khoáng vật tồn tại bên trong các đám pyrotin dưới dạng kiến trúc gặm mòn, thay thế, điều này phản ánh quá trình thành tạo trong giai đoạn sau của tổ hợp sphalerit-galenit (Hình 1f).

- Bismut tự sinh: Khoáng vật tương đối phổ biến với tần suất xuất hiện khoảng $10 \div 15 \%$ trong tập mẫu khoáng tướng, diện phân bố không đều.

Dưới kính hiển vi cho thấy bismut tự sinh thường gặp ở tập hợp dạng hạt tha hình với kích thước hạt dao động từ $0,05 \div 0,1 \mathrm{~mm}$, đôi khi còn gặp bismut tự sinh dạng hình cầu, hình bán lập phương xâm tán độc lập trên nền đá. Trong các mẫu, bismut tự sinh thường tồn tại ở hai kiểu kiến trúc: i) Thay thế, lấp đầy các khe nứt của những khoáng vật thành tạo trước (Hình 1h, 1i); ii) Xâm tán độc lập trên nền đá. Từ đó có thể nhận định rằng, bismut tự sinh thành tạo ở giai đoạn sau cùng với wolframit.

Ngoài các khoáng vật quặng chính mô tả trên, trong tập mẫu còn gặp một số ít các khoáng vật quặng khác với hàm lượng rất nhỏ như casiterit, ilmenit, đồng xám, rutil, leucoxen. Các khoáng vật quặng thứ sinh gồm: chalcozin, bocnit, covelin, melnhicovit,... Chúng là sản phẩm của quá trình oxy hóa các khoáng vật quặng sulfur nguyên sinh.

\subsection{2. Đặc điểm thành phần hóa học}

Để xác định hàm lượng các nguyên tố trong quặng, các mẫu được lấy chủ yếu trong các thân quặng wolfram, thiếc - đa kim phân bố trong các mạch thạch anh nhiệt dịch xuyên cắt đá phiến felspat - biotit và quarzit biotit hệ tầng Mường Na và trong đá granit biotit phức hệ Huổi Kút. Mẫu được gửi phân tích tại Nhật Bản.
Kết quả phân tích 36 mẫu bằng phương pháp ICP-MS, cho thấy các nguyên tố tạo quặng trong khu vực Huổi Chừn là $\mathrm{Cu}, \mathrm{Sn}, \mathrm{W}, \mathrm{Bi}, \mathrm{Pb}, \mathrm{Zn}, \mathrm{Co}, \mathrm{Ba}$, V. Các nguyên tố này tồn tại trong các khoáng vật phân bố trong các mạch thạch anh nhiệt dịch dưới dạng ổ hoặc dạng dải, chúng là sản phẩm của các giai đoạn nhiệt dịch khác nhau. Quá trình phân tích khoáng tướng kết hợp với phân tích thành phần hóa học quặng cho thấy rõ hơn về các giai đoạn tạo quặng tương ứng với những tổ hợp khoáng vật (nguyên tố) chiếm ưu thế của từng giai đoạn đó. Kết quả phân tích như sau:

- Nguyên tố $W$ : Có hàm lượng dao động từ $874 \div 4284$ ppm. $W$ phân bố đồng đều trong mạch thạch anh nhiệt dịch xuyên cắt các đá biến chất hệ tầng Mường $\mathrm{Na}$.

- Nguyên tố Cu: Hàm lượng từ 95 50.854 ppm. Loại phân bố dạng mạch, mạng mạch trong các mạch thạch anh nhiệt dịch xuyên cắt đá phiến tập 2 hệ tầng Mường $\mathrm{Na}$, hàm lượng $\mathrm{Cu}$ tăng cao (35.427 50.854 ppm); ngược lại, loại phân bố dạng xâm tán thường có hàm lượng thấp hơn

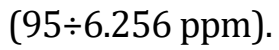

- Nguyên tố Bi: Chiếm hàm lượng lớn trong các mạch quặng, dao động từ $3.249 \div 4.873$ ppm, chủ yếu phân bố trong mạch thạch anh nhiệt dịch xuyên cắt đá phiến tập 2 hệ tầng Mường $\mathrm{Na}$.

- Nguyên tố Zn: Dao động từ 19:1.549 ppm. Zn tăng đột biến trong các mạch thạch anh nhiệt dịch xuyên cắt đá phiến tập 2 hệ tầng Mường $\mathrm{Na}$.

- Nguyên tố Ni: Có hàm lượng thấp, dao động từ

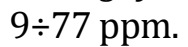

- Các nguyên tố $\mathrm{Pb}, \mathrm{Sn}, \mathrm{Mo}$ : Có hàm lượng thấp. Hàm lượng một số nguyên tố đi kèm (ppm): Ba

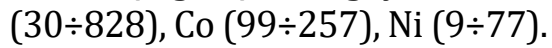

- Hàm lượng các nguyên tố hiếm - vết: Kết quả phân tích cho thấy, các nguyên tố đất hiếm nhẹ (LREE) như Ce, La có giá trị thấp. Các nguyên tố đất hiếm trung gian $(\mathrm{Nb})$ và đất hiếm nhóm nặng (Y) đều có giá trị rất thấp.

\subsection{3. Đặc điểm cấu tạo, kiến trúc quặng}

Các khoáng vật quặng trong khu vực nghiên cứu được thành tạo chủ yếu theo phương thức lắng đọng vật chất, kết tinh từ dung dịch nhiệt dịch, lấp đầy các hệ thống khe nứt. Do sự phân bố không đồng đều của các khoáng vật, nên quặng có cấu tạo khá đa dạng. Các cấu tạo quan sát được dưới kính là xâm tán, ổ, dải, mạch, trong đó cấu tạo ổ là phổ biến nhất. 


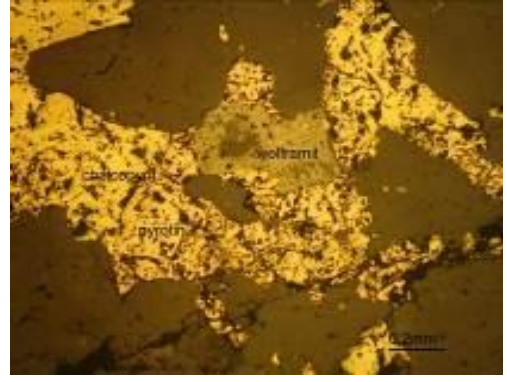

1a- Wolframit gặm mòn pyrotin (Mẫu L-015A)

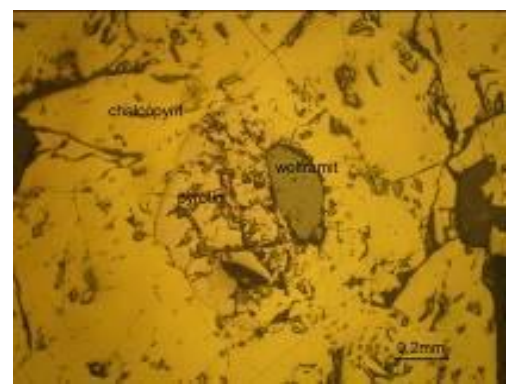

1d- Wolframit xen lấp pyrotin (Mẫu L-004)

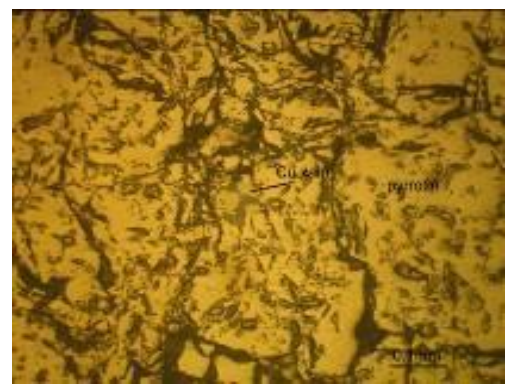

1g-Đồng xám xen lấp pyrotin (Mẫu L-032)

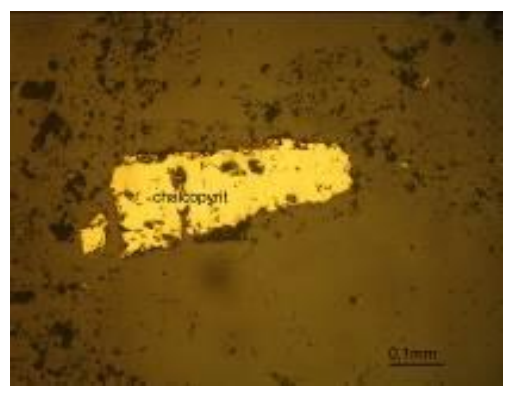

1j-Chalcopyrit tự hình xâm tán (Mẫu L-022)
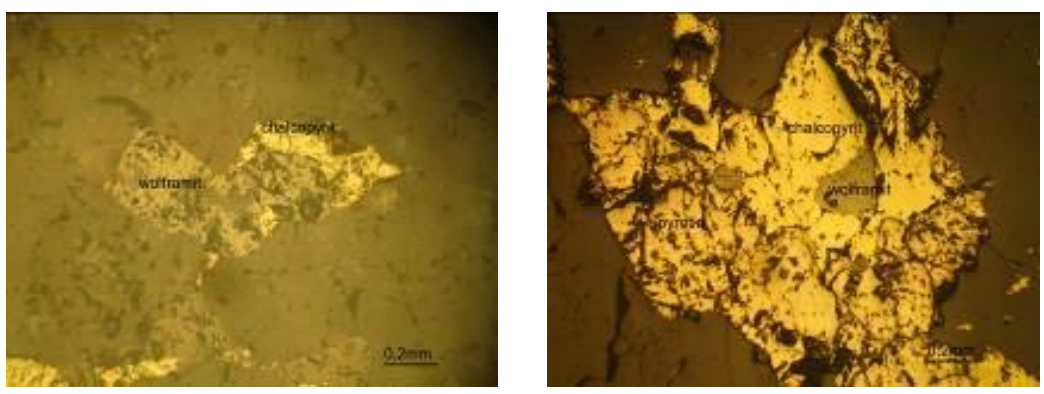

$1 b$ - Wolframit gặm mòn chalcopyrit 1c-Wolframit xen lấp chalcopyrit (Mẫu L-025)

(Mẫu L-015)

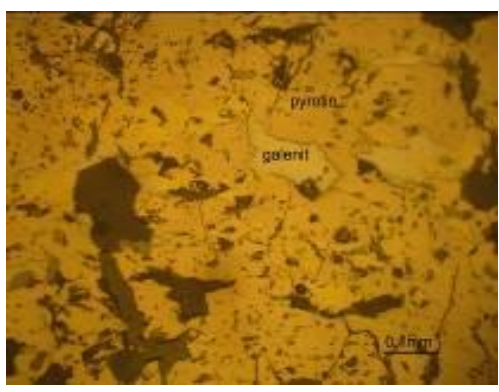

1e-Galenit xen lấp pyrotin (Mẫu L-015)

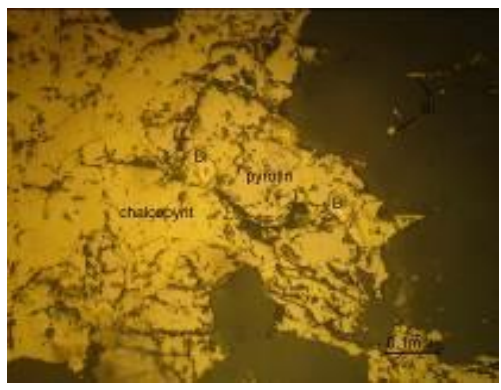

1h-Bismut xen lấp chalcopyrit (Mẫu L-015A)

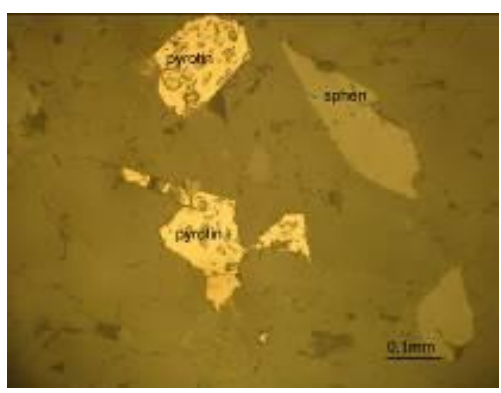

1k-Pyrotin tự hình xâm tán (Mẫu L-031/1)

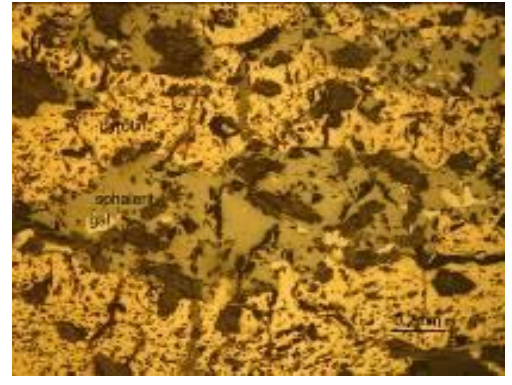

1f-Gal-Spha xen lấp pyrotin (Mẫu L-015A)

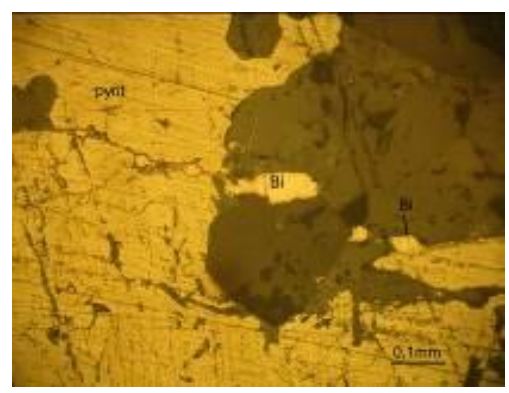

1i-Bismut lấp đầy các khe nút (Mẫu L-015)

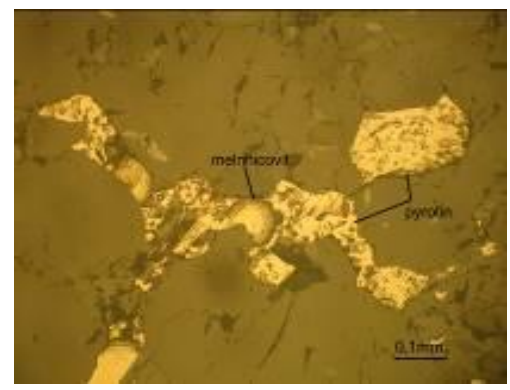

11- Khoáng vật thứ sinh (Mẫu L-031/2) 
Các khoáng vật quặng như chancopyrit, pyrotin, wolframit, galenit, sphalerit, bismut tập hợp thành những ổ đặc sít trong các mạch thạch anh. Cấu tạo dải và mạng mạch cũng tương đối phổ biến, đặc trưng cho tổ hợp cộng sinh khoáng vật quặng có chứa thiếc và đa kim. Ứng với mỗi khoáng vật và phương thức hình thành cũng có những đặc điểm kiến trúc riêng.

- Cấu tạo dạng ổ đặc sít: Đặc trưng cho các khoáng vật chalcopyrit, pyrotin và một phần là galenit, sphalerit, pyrit. Các khoáng vật quặng tập trung thành các ổ, nhìn bằng mắt thường hầu như đặc sít, kích thước mỗi ổ từ vài $m m$ đến $2 \div 3 \mathrm{~cm}$, phân bố trong các mạch thạch anh nhiệt dịch dày $10 \div 15 \mathrm{~cm}$, xuyên cắt đá phiến thạch anh - felspat biotit thuộc tập 2 hệ tầng Mường $\mathrm{Na}\left(\mathrm{PR}_{2} m n_{2}\right)$ hoặc phân bố trong các đới dập vỡ của hệ thống đứt gãy á vĩ tuyến.

- Cấu tạo xâm tán: Đặc trưng cho các khoáng vật chalcopyrit, pyrotin, pyrit, bismut tự sinh. Loại cấu tạo này thường gặp trong các mạch thạch anh xuyên cắt đá phiến tập 2 hệ tầng Mường $\mathrm{Na}\left(\mathrm{PR}_{2}\right.$ $m n_{2}$ ), ít phổ biến, các khoáng vật quặng phân bố xâm tán nhỏ lẻ trên nền thạch anh. Dưới kính quan sát thấy các hạt khoáng vật có hình dạng tự hình đến nửa tự hình, kích thước các hạt từ $0,2 \div 0,5$ mm. Mức độ xâm tán của các khoáng vật không đều và không theo một quy luật nhất định (Hình 2b).
- Cấu tạo dải: Loại cấu tạo này đặc trưng cho các khoáng vật casiterit, galenit, sphalerit, gặp phổ biến trong các mạch thạch anh dày $10 \div 15 \mathrm{~cm}$ xuyên cắt đá phiến tập 2 hệ tầng Mường $\mathrm{Na}\left(\mathrm{PR}_{2}\right.$ $m n_{2}$ ).

Bằng mắt thường quan sát thấy các khoáng vật tập trung thành dải với bề dày dao động từ $2 \div 5$ $\mathrm{mm}$, chiều dài của dải không ổn định, thường ngắt quãng. Tổ hợp cộng sinh khoáng vật cho cấu tạo này là galenit - sphalerit - ít casiterit (Hình 2c).

- Cấu tạo mạch, mạng mạch: Điển hình cho loại cấu tạo này là các khoáng vật thuộc thế hệ II như chalcopyrit, pyrotin, pyrit, sphalerit thường tạo thành các mạch lấp đầy vi khe nứt trong các mạch thạch anh xuyên cắt đá phiến tập 2 hệ tầng Mường $\mathrm{Na}\left(\mathrm{PR}_{2} \mathrm{mn}_{2}\right)$. Cấu tạo này đặc trưng cho quá trình thành tạo ở giai đoạn sau, xen lấp vào các khoáng vật sinh thành trước. Đặc biệt, các khoáng vật tạo quặng giai đoạn sau tạo thành các mạch xuyển lấp vào các khe nứt của khoáng vật tạo đá (Hình $2 \mathrm{~d}$ ). Quặng hóa trong vùng nghiên cứu tồn tại ở 2 nhóm kiến trúc nguyên sinh và thứ sinh. Nhóm kiến trúc nguyên sinh được thành tạo đồng thời với quá trình tạo quặng do sự trao đổi thay thế các khoáng vật thành tạo trước với dung dịch nhiệt dịch. Nhóm kiến trúc thứ sinh của quặng nguyên sinh hình thành sau quá trình tạo quặng, liên quan tới sự phá hủy kiến trúc sau tạo quặng, quặng bị cà nát, tái kết tinh, dập vỡ, định hướng.
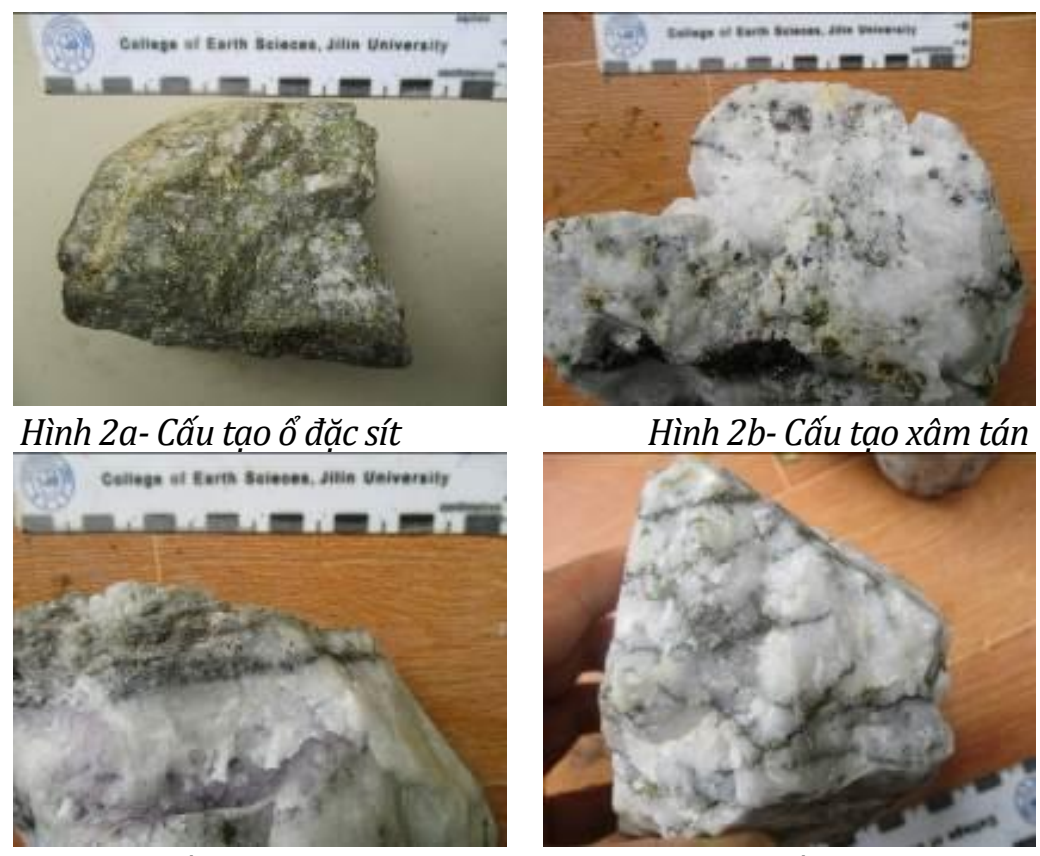

Hình 2c- Cấu tạo dạng dải
Hình $2 b$-Cấu tao xâm tán

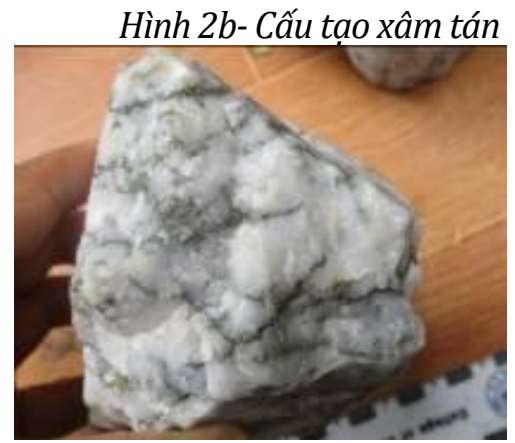

Hình 2d-Cấu tạo dạng mạch 
Các kết quả phân tích mẫu khoáng tướng lấy trong khu vực đã xác định các dạng kiến trúc sau:

- Kiến trúc hạt tự hình, nửa tự hình: Đặc trưng gồm các khoáng vật chalcopyrit, pyrotin, pyrit.

Chúng thường phát triển thành các tinh thể hoàn chỉnh, hình khối xâm tán trong các mạch thạch anh xuyên cắt đá phiến (Hình $1 \mathrm{j}, 1 \mathrm{k}$ ).

- Kiến trúc hạt tha hình: Là kiến trúc phổ biến nhất và gặp hầu hết trong các khoáng vật chalcopyrit, pyrotin, pyrit, wolframit, galenit, sphalerit, bismut tự sinh,... với kích thước thay đổi trong phạm vi rộng với nhiều hình dạng khác nhau (Hình 1a, 1c).

- Kiến trúc xen lấp: Phổ biến các khoáng vật như bismut tự sinh, wolframit xen lấp vào các khoáng vật chalcopyrit, pyrit và đá. Hình dạng và kích thước của các khoáng vật xen lấp phụ thuộc vào hình dạng và kích thước của khe nứt có trước (Hình 1d, 1i).

- Kiến trúc gặm mòn thay thế: Gặp trong một vài mẫu khoáng tướng. Có thể quan sát rõ các khoáng vật như bismut tự sinh, sphen gặm mòn thay thế các khoáng vật pyrit, pyrotin hoặc các khoáng vật tạo đá có trước (Hình 1a, 1b).

- Kiến trúc keo: Đặc trưng cho các khoáng vật thứ sinh thành tạo trong thời kỳ phong hóa.

Từ các kết quả phân tích thành phần khoáng vật, cấu tạo, kiến trúc, phân chia tổ hợp cộng sinh khoáng vật tương ứng với các quá trình thành tạo và biến đổi đá và quặng, có thể phân chia các thời kỳ và giai đoạn tạo khoáng wolfram, thiếc - đa kim trong khu vực Huổi Chừn (Bảng 1 ).

\subsubsection{Thú tự sinh thành và tổ hợp cộng sinh khoáng vật}

- Thò̀i kỳ nhiệt dịch: Gồm 3 giai đoạn:

+ Giai đoạn sớm (I): Đặc trưng bởi tổ hợp cộng sinh khoáng vật: chalcopyrit - pyrit - pyrotin;

+ Giai đoạn giữa (II): Đặc trưng bởi tổ hợp công sinh khoáng vật pyrotin casiterit - sphaleritgalenit - đồng xám;

+ Giai đoạn muộn (III): Đặc trưng bởi tổ hợp cộng sinh khoáng vật wolframit - bismut tự sinh.

Bảng 1. Thứ tự thành tạo và tổ hợp cộng sinh khoáng vật khu vực Huổi Chùn.

\begin{tabular}{|c|c|c|c|c|c|}
\hline Thời kỳ tạo khoáng & \multicolumn{3}{|c|}{ Nhiệt dịch } & \multirow[t]{2}{*}{ Sau nhiệt dịch } & \multirow[t]{2}{*}{ Phong hóa } \\
\hline Giai đoạn tạo khoáng & Giai đoạn sớm & Giai đoạn giữa & $\begin{array}{l}\text { Giai đoạn } \\
\text { muộn }\end{array}$ & & \\
\hline Tên KV THCSKV & $\begin{array}{l}\text { Chalcopyrit- } \\
\text { Pyrit-Pyrotin }\end{array}$ & $\begin{array}{c}\text { Pyrotin-Casiterit - } \\
\text { Sphalerit-Galenit-đồng } \\
\text { xám }\end{array}$ & $\begin{array}{l}\text { Wolframit - } \\
\text { Bismut tự sinh }\end{array}$ & $\begin{array}{l}\text { Thạch anh- } \\
\text { Calcit }\end{array}$ & $\begin{array}{l}\text { Chalcozin-Covelin- } \\
\text { Bornit-Melnhicovit }\end{array}$ \\
\hline Thach anh & $\overline{-}$ & 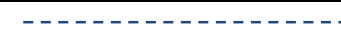 & 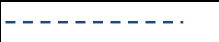 & & \\
\hline Calcit & & 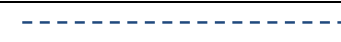 & |----- & & \\
\hline Chalcopyrit & 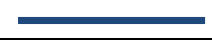 & $----------\cdot$ & & & \\
\hline Pyrotin & & & & & \\
\hline Pyrit & & ---------- & & & \\
\hline Sphalerit & & & & & \\
\hline Casiterit & & $=$ & & & \\
\hline Galenit & & 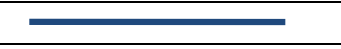 & & & \\
\hline Đồng xám & & 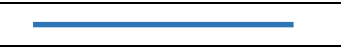 & & & \\
\hline Wolframit & & & & & \\
\hline Bismut tự sinh & & & & & \\
\hline Melnhicovit & & & & & \\
\hline Chalcozin & & & & & \\
\hline Covelit & & & & & - \\
\hline Bornit & & & & & $\bar{z}$ \\
\hline Nguyên tố đặc trưng & $\mathrm{Cu}$ & $\mathrm{Cu}, \mathrm{Zn}, \mathrm{Pb}, \mathrm{Sn}$ & $\mathrm{Co}, \mathrm{W}, \mathrm{Bi}$ & $\mathrm{Si}, \mathrm{Ca}$ & \\
\hline Kiến trúc đặc trưng & $\begin{array}{l}\text { Hạt tự hình, } \\
\text { nửa tự hình }\end{array}$ & Hạt tha hình & $\begin{array}{l}\text { Xen lấp, gặm } \\
\text { mòn }\end{array}$ & & \\
\hline Cấu tạo đặc trưng & Ổ đặc xít & Dải, mạng mạch & Xâm tán & & \\
\hline $\begin{array}{c}\text { Biến đổi đá vây } \\
\text { quanh }\end{array}$ & Chlorit hóa & Sericit hóa & Thạch anh hóa & $\begin{array}{c}\text { Thạch anh } \\
\text { hóa }\end{array}$ & \\
\hline — Khoáng vật ch & nủ yếu; & Khoáng vật th & yếu; & - - Khoáng & vật hiếm gặp. \\
\hline
\end{tabular}


- Thò̀i kỳ phong hóa: Gồm tổ hợp các khoáng vật thứ sinh: chalcozin - covelin - bornit melnhicovit.

\subsection{Mối quan hệ tương quan giữa nguyên tố trong quăgng}

Dựa vào kết quả phân ICP - MS 23 nguyên tố (36 mẫu), áp dụng công thức 1 xác định hệ số tương quan giữa các nguyên tố, kết quả tính hệ số tương quan cặp giữa các nguyên tố trích dẫn ở Bảng 2, 3, 4.

Bảng 2. Mối quan hệ tương quan của các nguyên tố $\mathrm{Sn}, \mathrm{Cu}, \mathrm{Pb}, \mathrm{Zn}, \mathrm{As}, \mathrm{Cd}$ và Bi.

\begin{tabular}{|c|c|c|c|c|c|c|}
\hline & $\mathrm{Sn}$ & $\mathrm{Cu}$ & $\mathrm{Pb}$ & $\mathrm{Zn}$ & $\mathrm{As}$ & $\mathrm{Cd}$ \\
\hline $\mathrm{Sn}$ & 1,00 & 0,96 & 0,80 & 0,96 & 0,62 & 0,94 \\
\hline $\mathrm{Cu}$ & & 1,00 & 0,69 & 0,99 & 0,43 & 0,84 \\
\hline $\mathrm{Pb}$ & & & 1,00 & 0,67 & 0,93 & 0,92 \\
\hline $\mathrm{Zn}$ & & & & 1,00 & 0,42 & 0,84 \\
\hline $\mathrm{As}$ & & & & & 1,00 & 0,83 \\
\hline $\mathrm{Cd}$ & & & & & & 1,00 \\
\hline
\end{tabular}

Bảng 3. Mối quan hệ tương quan của các nguyên tố $W, B, C o, V, S c$ và Bi.

\begin{tabular}{|c|c|c|c|c|c|c|c|c|c|c|}
\hline & W & B & Co & V & Sc & Bi & Sn & Cu & Pb & Zn \\
\hline W & 1,00 & 0,70 & 0,91 & $-0,63$ & $-0,66$ & 0,67 & 0,36 & 0,19 & 0,30 & 0,21 \\
\hline B & & 1,00 & 0,47 & 0,26 & 0,47 & 0,28 & 0,22 & 0,31 & 0,29 & 0,33 \\
\hline Co & & & 1,00 & 0,80 & 0,73 & 0,44 & 0,59 & 0,19 & 0,60 & 0,42 \\
\hline V & & & & 1,00 & 0,83 & -0.64 & $-0,67$ & $-0,65$ & $-0,53$ & $-0,63$ \\
\hline Sc & & & & & 1,00 & $-0,58$ & $-0,59$ & $-0,59$ & $-0,50$ & $-0,55$ \\
\hline Bi & & & & & & 1,00 & 0,96 & 0,99 & 0,66 & 1,00 \\
\hline Sn & & & & & & & 1,00 & 0,96 & 0,80 & 0,96 \\
\hline Cu & & & & & & & & 1,00 & 0,69 & 0,99 \\
\hline Pb & & & & & & & & & 1,00 & 0,67 \\
\hline Zn & & & & & & & & & & 1,00 \\
\hline
\end{tabular}

Bảng 4. Mối quan hệ tương quan của nguyên tố Li, La và $Y$.

\begin{tabular}{|c|c|c|c|}
\hline & $\mathrm{Li}$ & $\mathrm{La}$ & $\mathrm{Y}$ \\
\hline $\mathrm{Li}$ & 1,00 & 0,72 & 0,95 \\
\hline $\mathrm{La}$ & & 1,00 & 0,61 \\
\hline $\mathrm{Y}$ & & & 1,00 \\
\hline
\end{tabular}

Từ Bảng 2 nhận thấy, Sn có quan hệ thuận rất chặt chẽ với $\mathrm{Cu}, \mathrm{Pb}, \mathrm{Zn}, \mathrm{As}, \mathrm{Cd}$; đây là các nguyên tố đặc trưng của giai đoạn tạo khoáng II, với tổ hợp cộng sinh khoáng vật là pyrotin - casiterit sphalerit- galenit - đồng xám.

Từ Bảng 3 nhận thấy:

- $W$ có mối quan hệ chặt chẽ với $C o, B$ và $B i$ và có quan hệ không chặt chẽ với $\mathrm{Sn}, \mathrm{Cu}, \mathrm{Pb}$ và $\mathrm{Zn} ; \mathrm{V}$ có quan hệ chặt chẽ với Sc và giữa chúng có quan hệ nghịch với $\mathrm{W}, \mathrm{Bi}, \mathrm{Sn}, \mathrm{Cu}, \mathrm{Pb}$ và $\mathrm{Zn}$. Như vậy có thể khẳng định rằng các nguyên tố $\mathrm{W}$, Co và $\mathrm{Bi}$ đặc trưng cho giai đoạn tạo quặng III, tương ứng tổ hợp cộng sinh khoáng vật wolframit- bismut tự sinh (Bảng 1).

- Nguyên tố Bi có quan hệ rất chặt chẽ với $S n$, $\mathrm{Cu}, \mathrm{Zn}$ và $\mathrm{Cd}$; điều này có thể lý giải rằng: Trong khu vực nghiên cứu xảy ra quá trình tạo khoáng chồng, nghĩa là giai đoạn tạo khoáng III nằm chồng lên giai đoạn tạo khoáng II (?).

Từ Bảng 4 nhận thấy, Li có quan hệ rất chặt chẽ với La và $Y$, đây là tổ hợp nguyên tố nhóm đất hiếm, là các nguyên tố trong các khoáng vật tạo đá hoặc các khoáng vật biến đổi cạnh mạch (?).

\section{Kết luận}

1. Các khoáng vật quặng trong khu vực nghiên cứu được thành tạo chủ yếu theo phương thức lắng đọng vật chất, kết tinh từ dung dịch nhiệt dịch, lấp đầy các hệ thống khe nứt. Quặng hóa được hình thành có thể có liên quan đến hoạt động magma xâm nhập xảy ra trong giai đoạn Merozoi - Kainozoi (?). Do sự phân bố không đồng đều của các khoáng vật, nên quặng có cấu tạo khá đa dạng. Các cấu tạo quan sát được dưới kính là xâm tán, ổ, dải, mạch, trong đó cấu tạo ổ là phổ biến nhất. Cấu tạo dải và mạng mạch cũng tương đối phổ biến.

2. Thành phần khoáng vật quặng khu Huổi Chừn chủ yếu gồm chalcopyrit, pyrit, pyrorin, wolframit, bismut tự sinh, galenit, sphalerit; các khoáng vật quặng thứ yếu gồm ilmenit, rutil, leucoxen, menhilcovit, ilianit,... Các khoáng vật quặng như chancopyrit, pyrotin, wolframit, galenit, sphalerit, bismut, casiterit tập hợp thành những ổ đặc sít hoặc các vi mạch trong các mạch thạch anh. Đặc trưng cho tổ hợp cộng sinh khoáng vật quặng có chứa thiếc - đa kim, wolfram và bismut tự sinh có kiến trúc gặm mòn hoặc lấp đầy các khe nứt trong các mạch thạch anh. Ứng với mỗi khoáng vật và phương thức hình thành cũng có những đặc điểm kiến trúc riêng.

3. Quặng hóa khu vực Huổi Chừn được thành tạo trong thời kỳ tạo quặng nhiệt dịch, gồm 3 giai đoạn: i) Giai đoạn sớm (I), đặc trưng bởi tổ hợp công sinh khoáng vật: chalcopyrit - pyrit- pyrotin; ii) giai đoạn giữa (II), đặc trưng bởi tổ hợp cộng sinh khoáng vật pyrotin- sphalerit- galenit - đồng xám và iii) giai đoạn muộn (III), đặc trưng bởi tổ hợp cộng sinh khoáng vật wolframit- bismut tự 
sinh. Thời kỳ phong hóa gồm tổ hợp các khoáng vật thứ sinh: chalcozin - covelin - bornit melnhicovit.

4. Kết quả phân tích thành phần hóa học (ICPMS) cho thấy các nguyên tố chiếm hàm lượng cao gồm $\mathrm{Cu}, \mathrm{W}, \mathrm{Sn}, \mathrm{Zn}, \mathrm{Bi}$. Kết quả xác lập mối quan hệ tương quan thống kê giữa các nguyên tố chỉ ra rằng, tổ hợp nguyên tố $\mathrm{Sn}, \mathrm{Cu}, \mathrm{Pb}, \mathrm{Zn}, \mathrm{As}$ và $\mathrm{Cd}$ có mối quan hệ tương quan khá chặt chẽ với nhau; đây là các nguyên tố đặc trưng cho giai đoạn tạo quặng II và các nguyên tố $W$, Co và Bi đặc trưng cho giai đoạn tạo quặng III của thời kỳ tạo quặng nhiệt dịch.

\section{Lò̀i cảm ơn}

Đây là sản phẩm của đề tài cấp Nhà nước thuộc chương trình Nghị định thư, mã số NĐT.35.LA/17.

\section{Tài liệu tham khảo}

Dovjicov, A. E. (Cb), (1965). Địa chất miền Bắc Việt Nam (bản tiếng Việt). Nhà xuất bản Khoa học và Kỹ thuật.

Hoàng Phương, (1974). Báo cáo Địa chất nhóm tờ Sầm Nưa (Lào) tỷ lệ 1:50.000. Lưu trũ Cục Địa chất và Khoáng sản Lào.

Lê Duy Bách, Nguyễn Văn Hoành (đồng chủ biên), (1996). Địa chất và khoáng sản tờ Khang Khay - Mường Xén tỷ lệ 1:200.000. Lưu trũ Cục Địa chất và Khoáng sản Lào.

Nguyen Huu Hiep, Andrew Carter, Dao Bui Din, Trinh The Luc, Ngo Thi Kim, Vu Anh Dao, Phan
Van Binh, Nguyen Quang Huy, (2020). Quality characteristics of Ilmenit minerals in the south central of Vietnam by SEM and QEMSCAN analysis (Vietnamese). Journal of Mining and Earth Sciences 61 (2), 72-81.

Nguyễn Văn Đễ, (1974). Báo cáo Địa chất nhóm tờ Bản Chiềng tỷ lệ 1:50.000. Lưu trữ Địa chất, Hà Nội.

Pham Nhu Sang, Nguyen Tien Dung, Phan Thi Thanh Hien, Vo Thi Cong Chinh, (2020). The degree of chemical weathering in the Ba River basin, South Central Vietnam: Major-element geochemistry investigations of morden river sediments and sedimentary rocks (Vietnamese). Journal of Mining and Earth Sciences 61 (2), 82-91.

Tô Văn Thụ (cb), (1982). Địa chất và khoáng sản tờ Sầm Nưa (Lào) tỷ lệ 1:200.000. Lưu trũ Cục Địa chất và Khoáng sản Lào.

Trần Văn Trị, Vũ Khúc (đồng chủ biên), (2009). Địa chất và Tài nguyên Việt Nam, Nhà xuất bản Khoa học tự nhiên và Công nghệ, Hà Nội.

Vũ Đức Lân (cb), (2016). Báo cáo kết quả công tác thăm dò quặng đa kim block 2 mỏ thiếc, chì, kẽm Huổi Chừn, huyện Mường Quắn, tỉnh Hủa Phăn, Cộng hòa dân chủ nhân dân Lào. Lưu trũ Công ty Cổ phần khoáng sản Lào - Việt.

Vũ Huy Chừng (cb), (1974). Báo cáo địa chất kết quả khảo sát quặng sắt và các kim loại khác trong vùng giải phóng Lào. Luu trũ Địa chất. 